\title{
Enhanced biohydrogen production from beverage industrial wastewater using external nitrogen sources and bioaugmentation with facultative anaerobic strains
}

ARTICLE in JOURNAL OF BIOSCIENCE AND BIOENGINEERING · DECEMBER 2014

Impact Factor: 1.79 · DOI: 10.1016/j.jbiosc.2014.12.011

DOWNLOADS

54

7 AUTHORS, INCLUDING:

Gopalakrishnan Kumar

National Institute for Environmental Studies

41 PUBLICATIONS 164 CITATIONS

SEE PROFILE

Periyasamy Sivagurunathan

Daegu University

15 PUBLICATIONS 39 CITATIONS

SEE PROFILE
VIEWS

53
Péter Bakonyi

University of Pannonia, Veszprém

26 PUBLICATIONS 98 CITATIONS

SEE PROFILE

Chiu-Yue Lin

Feng Chia University

323 PUBLICATIONS $\quad 6,229$ CITATIONS

SEE PROFILE 


\section{Enhanced biohydrogen production from beverage industrial wastewater using external nitrogen sources and bioaugmentation with facultative anaerobic strains}

Gopalakrishnan Kumar ${ }^{1 *}$, Péter Bakonyi ${ }^{2}$, Sivagurunathan Periyasamy ${ }^{3}$, Sang-Hyoun Kim ${ }^{1}$, Nándor Nemestóthy ${ }^{2}$, Katalin Bélafi-Bakó ${ }^{2}$, Chiu-Yue Lin ${ }^{3}$

${ }^{1}$ Department of Environmental Engineering, Daegu University, Gyeongsan, Gyeongbuk 712-

714, Republic of Korea

${ }^{2}$ Research Institute on Bioengineering, Membrane Technology and Energetics, University of Pannonia, Egyetem ut 10, 8200 Veszprém, Hungary

${ }^{3}$ Department of Environmental Engineering and Science, Feng Chia University, Taichung 40724, Taiwan

*Corresponding Author: Gopalakrishnan Kumar, Tel: +886-4-24517250 ext. 6259; Fax: +886-435072114; E-mail: gopalakrishnanchml@ gmail.com 


\begin{abstract}
In this work biohydrogen generation and its improvement possibilities from beverage industrial wastewater were sought. Firstly, mesophilic hydrogen fermentations were conducted in batch vials by applying heat-treated $\left(80{ }^{\circ} \mathrm{C}, 30 \mathrm{~min}\right)$ sludge and liquid (LB-grown) cultures of Escherichia coli (XL1-Blue)/Enterobacter cloacae (DSM 16657) strains for bioaugmentation purposes. The results showed that there was a remarkable increase in hydrogen production capacities when facultative anaerobes were added in the form of inoculum. Furthermore, experiments were carried out in order to reveal whether the increment occurred either due to the efficient contribution of the facultative anaerobic microorganisms or the culture ingredients (in particular yeast extract and tryptone) supplied when the bacterial suspensions (LB media-based inocula) were mixed with the sludge. The outcome of these tests was that both the applied nitrogen sources and the bacteria (E. coli) could individually enhance hydrogen formation. Nevertheless, the highest increase took place when they were used together. Finally, the optimal initial wastewater concentration was determined as $5 \mathrm{~g} / \mathrm{L}$.
\end{abstract}

Keywords: bioaugmentation, Escherichia coli (XL1-Blue), Enterobacter cloacae (DSM 16657), external nitrogen source 


\section{Introduction}

Due to the climate issues and concerns about the current fossil-based energy systems, a remarkable and world-wide progress in the research of environmental-benign and renewable energy carriers has started in the last couple of decades. Up to now, a large variety of alternative biofuels have been investigated and biologically produced hydrogen is considered as a possible solution for the future because of its unique characteristics [1]. Among the different approaches to generate biohydrogen, the so-called dark fermentative way seems to be a potential candidate for large-scale applications from economical and practical point of views [2, 3]. During dark fermentation, hydrogen is formed from different organic compounds via the metabolic activity of specific microorganisms. The process is affected by a number of factors such as temperature, $\mathrm{pH}$, carbon and nitrogen sources and the composition of the microbial consortia $[4,5]$. Recently, enormous efforts have been put to make dark fermentation even more competitive, however, mostly simple, pure substrates were used and therefore the utilization of industrial waste streams still receives particular interest [6].

In general, the bioconversion of such complex materials into hydrogen requires a good cooperation of diverse microbial consortia that can usually be found in sewage sludge, anaerobic digesters, etc. However, sludge pretreatment is mostly compulsory in order to suppress the activity of methanogenic species or in other words, to help the selective growth of the potential hydrogen producers. The range of proven pretreatment techniques includes heat-shock, chemical agents (chloroform), acidic/alkali pretreatment, aeration, freezing and thawing, etc. [6]. Among them, heat-pretreatment is definitely the most widely and routinely employed since it is relatively fast, easy to conduct and efficient [7]. However, its drawback is that it could inhibit some of the 
reliable hydrogen producers, as well $[3,6]$. In most cases when heat treatment is applied it could observed that the mixed microbial community was strongly dominated by spore-forming species (e.g. Clostridia) and non sporulative hydrogen fermenting bacteria such as facultative anaerobes like the members of Enterobacteriaceae could not survive. This reduction in the microbial diversity of the mixed culture might bring disadvantages in process efficiency. Consequently, the bioaugmentation of heat-treated sludge with facultative anaerobic strains might result in the improvement of hydrogen production. Moreover, in studies when their pure cultures were used some significant achievements have been published, however, mostly with simple substrates [8]. Hence, investigating the possibility related to bioaugmented hydrogen production by applying various facultative anaerobes could be an interesting field of research. Up to authors' best knowledge, no biohydrogen research has been conducted on industrial wastes using bioaugmented, heat-treated inocula. Therefore, in this study, bioaugmentation of mesophilic hydrogen fermentation by employing two facultative anaerobic organisms, Escherichia coli (XL1-Blue) and Enterobacter cloacae (DSM 16657) was carried out from beverage industrial wastewater under different culture conditions. Alongside these tests, the effect of external nutrient (tryptone, yeast extract) addition was also sought since previously it was demonstrated that supplementation with such nitrogen sources led also to enhanced hydrogen generation [9].

\section{Material and Methods}

\section{Bacterial source}

Escherichia coli (XL1-Blue) and Enterobacter cloacae (DSM 16657) strains were supplied by University of Pannonia, Veszprem, Hungary as a part of a scientific program with Feng Chia 
University, Taiwan. Sewage sludge was obtained from a local water treatment plant Taichung, Taiwan. The collected sludge was stored in refrigerator at $4{ }^{\circ} \mathrm{C}$ and heat-pretreated at $80{ }^{\circ} \mathrm{C}$ for 30 minutes prior to use. In accordance with our previous paper [10], the method of optical density at $620 \mathrm{~nm}\left(\mathrm{OD}_{620}\right)$ was employed to follow the biomass growth in the inoculum of the pure cultures mentioned above. LB media was used to prepare the inoculum of the facultative anaerobic bacteria mentioned and their overnight cultures were applied for bioaugmentation purposes.

\section{Beverage industrial wastewater}

The wastewater feedstock was collected from a beverage industrial company located in central Taiwan. The characteristics of the beverage wastewater (BWW) were $\mathrm{pH} 2.6-3.4,760-900 \mathrm{~g}$ $\mathrm{COD} / \mathrm{L}$ and total reducing sugar of $660-750 \mathrm{~g}_{\text {(glucose equivalent }} / \mathrm{L}$. From that, a $40 \mathrm{~g} \mathrm{COD} / \mathrm{L}$ stock solution was prepared and used in the experiments indicated in Table 1, 2, 4, 5. The wastewater was kept at $4{ }^{\circ} \mathrm{C}$ in order to avoid any biological changes and during the experiments the $40 \mathrm{~g}$ $\mathrm{COD} / \mathrm{L}$ stock solution was diluted to get the desired substrate (COD) concentrations.

\section{Hydrogen fermentation}

Batch fermentations were carried out in vials having a total capacity of $225 \mathrm{~mL}$. The working volume of $160 \mathrm{~mL}$ with various compositions listed in Table 1, 2, 4 and 5 were prepared. Slightly acidic initial $\mathrm{pH}$ was selected and adjusted to $6.5[6,11]$. The bottles were purged with argon gas for 10 minutes in order to ensure anaerobic conditions, subsequently sealed and placed in a reciprocal air-bath shaker at $150 \mathrm{rpm}$ with temperature control at $37{ }^{\circ} \mathrm{C}$. The nutrient solution used in this study was slightly different from the Endo formulation [12] and contained the 
following ingredients (mg/L): $125 \mathrm{~K}_{2} \mathrm{HPO}_{4}, 100 \mathrm{MgCl}_{2} \cdot 6 \mathrm{H}_{2} \mathrm{O}, 15 \mathrm{MnSO}_{4} \cdot 6 \mathrm{H}_{2} \mathrm{O}, 25 \mathrm{FeSO}_{4} \cdot 7 \mathrm{H}_{2} \mathrm{O}$, $5 \mathrm{CuSO}_{4} \cdot 5 \mathrm{H}_{2} \mathrm{O}$, and $0.12 \mathrm{CoCl}_{2} \cdot 5 \mathrm{H}_{2} \mathrm{O}$. The volume of biogas produced was measured by air-tight glass syringe and composition was determined periodically by gas chromatography as described elsewhere $[13,14]$. Fermentations were terminated when no further gas production could be observed. All the measurements were carried out in triplicates and results are given as their mathematical averages.

\section{Modified Gompertz equation}

Modified Gompertz equation (Eq. 1) was used to get the kinetic parameters such as hydrogen production potential $(P)$, maximum hydrogen production rate $\left(R_{m}\right)$ and lag phase time $(\lambda)$ under different experimental conditions (Table 3). The software details are Sigma plot software 10.0 (Systat Software Inc., USA).

$$
H(t)=P \cdot \exp \left\{-\exp \left[\frac{R_{m} \cdot e}{P}(\lambda-t)+1\right]\right\}
$$

where $H(t)$ represents the cumulative hydrogen production $(\mathrm{mL}) ; P$ is the hydrogen production potential $(\mathrm{mL}) ; R_{m}$ is the maximum hydrogen production rate $(\mathrm{mL} / \mathrm{h}) ; e$ is $2.718 ; \lambda$ is the duration of lag phase (h) and $t$ is the cultivation time (h). Hydrogen Production Rate (HPR; $\mathrm{L} \mathrm{H}_{2} / \mathrm{L}$-d) was defined as $R_{m}$ value divided by the working volume of the reactor and multiplied with a day in hours (24 h). Hydrogen yield ( $\mathrm{HY} ; \mathrm{mL} \mathrm{H}_{2} / \mathrm{g} \mathrm{COD}$ added) was calculated as the cumulative hydrogen production $(\mathrm{mL})$ divided by the substrate (COD) added. 


\section{PCR amplification of genomic DNA}

Total genomic DNA from the enriched mixed cultures was extracted by using the Blood \& Tissue Genomic DNA Extraction Miniprep System (Viogene, Taiwan) following the manufacturer's instructions. PCR primers employed for the amplification of 16S rDNA was, the eubacterial primer set (forward primer Eub968f with GC clamp and reverse primer Univ1392r) [15]. The PCR amplification and DGGE analysis were performed in accordance with the method described in our previous study [14].

\section{Results and Discussion}

Hydrogen fermentation from beverage wastewater using heat-pretreated, bioaugmented sewage sludge

The effect of bioaugmentation on hydrogen production was studied by the addition of facultative anaerobic strains belonging to Enterobacteriaceae, namely Escherichia coli and Enterobacter cloacae. These microbes were proven to be robust and efficient hydrogen producers by different scientists. For example, Kumar and Das [16] used E. cloacae for hydrogen production and attractive yields and production rates were reported from various substrates e.g. glucose, fructose, sucrose, xylose, cellobiose, etc . In another publication, Ghosh and Hallenbeck [17] applied E. coli for biotechnological hydrogen generation from substrates covering disaccharides (e.g. lactose, sucrose, maltose), monohexoses (e.g. glucose, fructose, galactose) and monopentoses (e.g. xylose, arabinose), as well. It was revealed that these microorganisms could sufficiently transform this wide range of carbon sources to hydrogen and therefore, E. cloacae and E. coli can be considered as promising bacteria for viable hydrogen fermentation $[16,17]$. However, still only a limited knowledge is available on hydrogen production from complex 
substrates using mixed cultures and the above mentioned pure cultures, as well. Consequently, in this study, beverage industrial wastewater was used as carbon source for bioaugmented hydrogen generation.

Firstly, $5 \mathrm{~g}$ COD/L was chosen as initial BWW substrate concentration and 5 various experimental runs were carried out according to Table 1. The obtained fermentation profiles are depicted in Fig. 1. As it can be seen in Table 1, E. coli (XL1-Blue), E. cloacae (DSM 16657) and their mixture (1:1 ratio) were added as overnight cultures grown in liquid Luria-Bertani (LB) media. Based on spectrophotometric calibration curves $\left(\mathrm{OD}_{620}\right), 40 \mathrm{~mL}$ was calculated as the required inoculums size in order to ensure an initial cell density of $0.1 \mathrm{~g}$ dry cell weight/L in the broth.

Evaluating the results in Fig. 1, it can be concluded that addition of liquid cultures regardless of the bacteria could significantly affect both the hydrogen production rate (HPR) and yield (HY), which could possibly be attributed to two different reasons. On one hand, it might occurred due to the efficient contribution of the applied strains. On the other hand, it could be the outcome of the nutrients (e.g. yeast extract, tryptone) supplementation along with the bacteria. These materials are the main ingredients of LB medium - which was employed to prepare the overnight inocula of the pure cultures - and could reportedly enhance the hydrogen production efficiency [9]. Furthermore, based on Table 3 it can be pointed out that the highest improvement could be achieved when the heat-treated sludge was bioaugmented by E. coli (XL1-Blue), followed by mixture of E. coli (XL1-Blue) and E. cloacae (DSM 16657) (50:50\%) and the E. cloacae (DSM 16657) alone. 
Hydrogen generation from beverage wastewater using pure cultures of $E$. coli (XL1-Blue) and E. cloacae (DSM 16657)

Measurements were conducted with the pure cultures of the facultative anaerobic bacteria (Table 2) in order to seek whether the E. coli (XL1-Blue), E. cloacae (DSM 16657) or their mixture possess the ability of producing hydrogen from the beverage waste water or not. The applied initial wastewater COD concentration and cell density were adjusted as previously to $5 \mathrm{~g} \mathrm{COD} / \mathrm{L}$ and $0.1 \mathrm{~g} \mathrm{dcw} / \mathrm{L}$, respectively.

The results are shown in Fig. 2, where it can be seen that hydrogen could be formed quite satisfactory, however a bit surprisingly, the progress curves in Fig. 2 were remarkably different compared to those in Fig. 1. From the data listed in Table 3 it can be drawn that biohydrogen fermentation employing these facultative anaerobe strains can be characterized by a prolonged lag phase in the following order: E. cloacae (DSM 16657) < E. coli (XL1-Blue): E. cloacae (DSM 16657) $(50: 50 \%)<$ E. coli (XL1-Blue). Furthermore, unlike to the results in Fig 1, in the pure culture system the E. cloacae (DSM 16657) provided the highest HPR value, followed by the mixture of E. coli (XL1-Blue) and E. cloacae (DSM 16657) and E. coli (XL1-Blue). However, in terms of HY still E. coli was shown to be the most attractive. As a conclusion, the outcomes imply that the applied microorganisms could possibly contribute to the enhancement of biohydrogen formation but their behavior seems to be different in pure cultures and when used together with the heat-treated sewage sludge. 


\section{Dissecting the roles of bioaugmentation and nitrogen source supplementation on biohydrogen production}

Experiments were designed (Table 4) and performed in order to further clarify the particular reasons beyond the observed improvements in hydrogen generation. In these runs, only E. coli (XL1-Blue) was chosen since considering the results in Fig. 1 and Table 3 with respect to Table 1, the highest increase could be obtained with this whole cell biocatalyst. The results illustrated in Fig. 3c indicates that the addition of E. coli (XL1-Blue) cell mass itself could slightly enhance the hydrogen production process and therefore, it would appear that the bioaugmentation by facultative anaerobe strain like E. coli (XL1-Blue) can have individual impact on the attainable efficiency. Based on the results, it seems that E. coli (XL1-Blue) may act as a useful part of the originally Clostridia-dominated microbial consortia, thus its application in the enrichment of the heat-pretreated sludge could yield positive outcome.

Biohydrogen fermentation is typically a growth-associated progress, which is highly dependent on the sufficient nutrient supply e.g. the availability organic nitrogen compounds. During fermentation they are consumed from the reaction mixture and further bioconverted into nitrogenous cell matter e.g. proteins, nucleic acid, enzymes that are crucial for sufficient proliferation. For example, Ferchichi et al. [9] investigated the effect of numerous process parameters on hydrogen production encompassing nitrogen sources, as well. It was found that among the different kinds, complex materials e.g. yeast extract were favorable to improve biohydrogen production rate and yield [9]. As it can be seen in Fig.3b, the process efficiency was enhanced after the addition of external nitrogen sources such as yeast extract and tryptone. The reason is probably attributed to the fact that these compounds could induce a more efficient 
growth of the various bacterial groups present in the sludge and hence, boost the hydrogen production. However, the promising opportunities related to additional nutrient supplementation should be further assessed for real case applications due to the economical considerations of wastewater treatment.

In addition, the effect of nutrient addition was found to be more noticeable compared to simple enrichment with E. coli (XL1-Blue). Nevertheless, in Fig. 3d it is indicated that the highest enhancement took place when E. coli (XL1-Blue) and LB media were used altogether, which means that bioaugmentation along with organic nitrogen (yeast extract, tryptone) supplementation would appear as a beneficial strategy to increase the whole biohydrogen process performance.

In the course of the next measurements, the hydrogen production was optimized in terms of BWW concentration, during which COD was ranged between 2-20 g COD/L. Two series of experiments were carried out. In one, the combination of the heat-pretreated sludge and E. coli (XL1-Blue) in overnight LB media, while in the other heat-pretreated sludge was applied separately as seed source (Table 5). The optimization results are presented in Fig. 4, where it can be noticed that $\mathrm{HY}$ has a clear peak value of $256 \mathrm{~mL} \mathrm{H}_{2} / \mathrm{g}$ COD at substrate (BWW COD) concentration of $5 \mathrm{~g} / \mathrm{L}$ when bioaugmentation with E. coli (XL1-Blue) inoculum was employed. Therefore, this experimental set was considered as the optimal one. Besides, a remarkable improvement could be attained in terms of $\mathrm{HY}$ in all the cases of enrichment with E. coli inoculum irrespective of the initial COD concentration used.

Although hydrogen production performance has increased via bioaugmentation, an issue to be considered is the economic feasibility of the process. In fact, for an attractive technology, the augmented strains must survive and remain competitive during continuous culture conditions. 
Considering already published literature results, it has been evidenced that the augmented pure cultures remained active during the continuous, non-sterile operation [18]. According to those observations, it would appear that augmentation could nicely contribute to the intensification of biohydrogen fermentation taking place in practical circumstances. Nevertheless, current research focused only on batch measurements and therefore, in the future, we aim to conduct proof-ofconcept investigation in continuous mode operation, as well. Even though the optimum substrate concentration in this study was found at a relatively low level $(5 \mathrm{~g} \mathrm{COD} / \mathrm{L})$ that might influence economic viability, it is to note that the optimum substrate concentrations, in fact, vary with the type of feedstock and inoculum. The optimal substrate concentration of $5 \mathrm{~g} \mathrm{COD} / \mathrm{L}$ in this work was accompanied by fair hydrogen production performances. Furthermore, the spent media (residue of hydrogen biosynthesis) can be subjected to auxiliary methods such as anaerobic digestion, microbial fuel cells, etc. to harness further energy and enhance the overall process.

\section{Microbial community profiling}

In any fermentation process the microbial community structure is highly important to know in order to reproduce the results and as well as to recover the process in case of sudden operational failure. The assessment of microbial background by PCR-DGGE based on the 16S rDNA analysis is well-accepted in hydrogen production processes $[19,20]$. In this study the denaturing gradient concentration of $40 \%$ to $60 \%$ was used to separate the band pattern of the different microbial community. Each band on the DGGE profile corresponds to a fragment of 16S rDNA sequences and represents a particular species in the microbial community [21].

A previous report has also used bioaugmentation strategy and reported that facultative anaerobes consume the oxygen and create strict anaerobic conditions for Clostridium species, thus this 
synergistic effect had increased the production performances [22]. However, the microbial community analysis has not been reported. Microbial profiling of this current research for the final bioaugmented fermentation culture (sewage sludge $+E$. coli) reveled that there were 6 major bands detected during the analysis and they belong to Clostridium perfringens, Clostridium tertium, Clostridium butyricum, Clostridium indolis and Escherichia Coli. The results are demonstrated in Fig 5, while Table 6 summarizes the soluble metabolic products determined and COD mass balance for the optimal fermentation conditions. Previous studies have reported that Clostridium spp. are good hydrogen producers and they survive during the heat pretreatment $[23,24]$. Our findings also confirm that the heat treatment has enriched the Clostridium spp. The heat pre-treatment used for eliminating hydrogen-consuming bacteria would also result in microbial community reduction. Since non-spore hydrogen producers are potentially destroyed by heat and Clostridia spp. are promoted, the external addition of facultative anaerobic bacteria might improve the hydrogen production performance, as suggested by the results of this study.

In this work biohydrogen was produced from beverage industrial wastewater under different experimental circumstances. It was turned out that both bioaugmentation of the heat-pretreated sludge with facultative anaerobic strains and supplementation with extra nutrients such tryptone and yeast extract could significantly enhance hydrogen generation regardless of the wastewater COD concentration applied. Therefore, it would appear that these approaches may be taken into account as strategies for increasing the overall performance of biohydrogen fermentation system.

\section{Acknowledgements}


This work was partially supported by the European Union and financed by the European Social Fund in the frame of the TAMOP-4.2.2/A-11/1/KONV-2012-0071 project and the János Bolyai Research Scholarship of the Hungarian Academy of Sciences. The authors also gratefully acknowledge the financial supports by Taiwan's Bureau of Energy (grant no. 102-D0616) and Taiwan's Minstry of Science and Technology (NSC-102-2221-E-035-002-MY3 and NSC-1022622E-035-016-CC1).

\section{References}

1. Kumar G. S., Kumari, S., Reddy, K. and Bux, F.: Trends in biohydrogen production: Major challenges and state-of-the-art developments, Environ. Technology, 34, 1653-1670 (2013).

2. Manish, S. and Banerjee, R.: Comparison of biohydrogen production processes, Int. J. Hydrogen Energy, 33, 279-286 (2008).

3. Li, C. and Fang, H. H. P.: Fermentative hydrogen production from wastewater and solid wastes by mixed cultures, Crit. Rev. Environ.Sci. Technol, 37, 1-39 (2007).

4. Hawkes, F. R., Dinsdale, R., Hawkes, D. L. and Hussy, I.: Sustainable fermentative hydrogen production: Challenges for process optimisation, Int. J. Hydrogen Energy, 27, 13391347 (2002).

5. Hallenbeck, P. C.: Fermentative hydrogen production: Principles, progress, and prognosis, Int. J. Hydrogen Energy, 34, 7379-7389 (2009).

6. Mathews, J. and Wang, G.: Metabolic pathway engineering for enhanced biohydrogen production, Int. J. Hydrogen Energy, 34, 7404-7416 (2009).

7. Bakonyi, P., Borza, B., Orlovits, K., Simon, V., Nemestóthy, N. and Bélafi-Bakó, K.: Fermentative hydrogen production by conventionally and unconventionally heat pretreated seed cultures: A comparative assessment, Int. J. Hydrogen Energy, 39, 5589-5596 (2014).

8. Lee, D. J., Show, K. Y. and Su, A.: Dark fermentation on biohydrogen production: Pure culture, Bioresour. Technol, 102, 8393-8402 (2011). 
9. Ferchichi, M., Crabbe, E., Hintz, W., Gil, G. H. and Almadidy, A.: Influence of culture parameters on biological hydrogen production by Clostridium saccharoperbutylacetonicum ATCC 27021, World J. Microbiol. Biotechnol, 21, 855-862 (2005).

10. Bakonyi, P., Nemestóthy, N., Ramirez, J., Ruiz-Filippi, G. and Bélafi-Bakó, K.: Escherichia coli (XL1-BLUE) for continuous fermentation of $\mathrm{bioH}_{2}$ and its separation by polyimide membrane, Int. J. Hydrogen Energy, 37, 5623-5630 (2012).

11. Bakonyi, P., Nemestóthy, N. and Bélafi-Bakó, K.: Comparative study of various E. coli strains for biohydrogen production applying response surface methodology, Sci. World J.

819793, (2012).

12. Endo, G., Noike, T., and Matsumoto, T: Characteristics of cellulose and glucose decomposition in acidogenic phase of anaerobic digestion, Proc. Soc.Civ. Eng, 325, 61-68 (1982).

13. Kumar, G., Lay, C. H., Chu, C. Y., Wu, J. H., Lee, S. C. and Lin, C. Y.: Seed inocula for biohydrogen production from biodiesel solid residues, Int. J. Hydrogen Energy, 37, 1548915495 (2012).

14. Sivagurunathan, P., Sen, B. and Lin, C.-Y.: Batch fermentative hydrogen production by enriched mixed culture: Combination strategy and their microbial composition, J. Biosci. Bioeng, 117, 222-228 (2014).

15. Nielsen, A. T., Liu, W. T., Filipe, C., Grady Jr, L., Molin, S. and Stahl, D. A.: Identification of a novel group of bacteria in sludge from a deteriorated biological phosphorus removal reactor, Appl. Environ. Microbiol, 65, 1251-1258 (1999).

16. Kumar, N. and Das, D.: Enhancement of hydrogen production by Enterobacter cloacae IIT-BT 08, Proc. Biochem, 35, 589-593 (2000).

17. Ghosh, D. and Hallenbeck, P. C.: Fermentative hydrogen yields from different sugars by batch cultures of metabolically engineered Escherichia coli DJT135, Int. J. Hydrogen Energy, 34, 7979-7982 (2009).

18. Pattra, S., Lay, C.-H., Lin, C.-Y., O-Thong, S. and Reungsang, A.: Performance and population analysis of hydrogen production from sugarcane juice by non-sterile continuous 
stirred tank reactor augmented with Clostridium butyricum, Int. J. Hydrogen Energy, 36, 86978703 (2011).

19. Zhang, K., Ren, N., Guo, C., Wang, A. and Cao, G.: Effects of various pretreatment methods on mixed microflora to enhance biohydrogen production from corn stover hydrolysate, J. Environ. Sci, 23, 1929-1936 (2011).

20. Phummala, K., Imai, T., Reungsang, A., Chairattanamanokorn, P., Sekine, M., Higuchi, T., Yamamoto, K. and Kanno, A.: Delignification of disposable wooden chopsticks waste for fermentative hydrogen production by an enriched culture from a hot spring, J. Environ. Sci, 26, 1361-1368 (2014).

21. Lin, Y.-H., Juan, M.-L. and Hsien, H.-J.: Effects of temperature and initial pH on biohydrogen production from food-processing wastewater using anaerobic mixed cultures, Biodegradation, 22, 551-563 (2011).

22. Qian, C. X., Chen, L. Y., Rong, H. and Yuan, X. M.: Hydrogen production by mixed culture of several facultative bacteria and anaerobic bacteria. Prog.Nat. Sci.Mat. Int, 21, 506-511 (2011).

23. Kawagoshi, Y., Hino, N., Fujimoto, A., Nakao, M., Fujita, Y., Sugimura, S. and Furukawa, K.: Effect of inoculum conditioning on hydrogen fermentation and $\mathrm{pH}$ effect on bacterial community relevant to hydrogen production, J.Biosci. Bioeng, 100, 524-530 (2005).

24. Baghchehsaraee, B., Nakhla, G., Karamanev, D., Margaritis, A. and Reid, G.: The effect of heat pretreatment temperature on fermentative hydrogen production using mixed cultures, Int. J. Hydrogen Energy, 33, 4064-4073 (2008).

25. Metcalf \& Eddy., T., G., Burton, F. L. 1., \& Stensel, H. D. (2003). Wastewater engineering: Treatment and reuse (4th ed.). Boston: McGraw-Hill. 


\section{Figure captions}

Fig.1: Fermentation profiles for testing bioaugmentation effect.

Fig. 2: Progress curves for the pure culture experiments.

Fig. 3: Time profiles of experiments testing the individual effects of E. coli (XL1-BLUE) and external nitrogen sources on hydrogen production.

Fig. 4: Results of wastewater COD optimization. Experimental conditions are listed (A-B) in Table 5.

Fig. 5: DGGE banding patterns of 16S rRNA genes from bioaugmented mixed cultures using universal eubacterial primer set under optimal conditions for biohydrogen production from BWW. The numbers in the lanes indicates DNA bands that were excised and sequenced. 


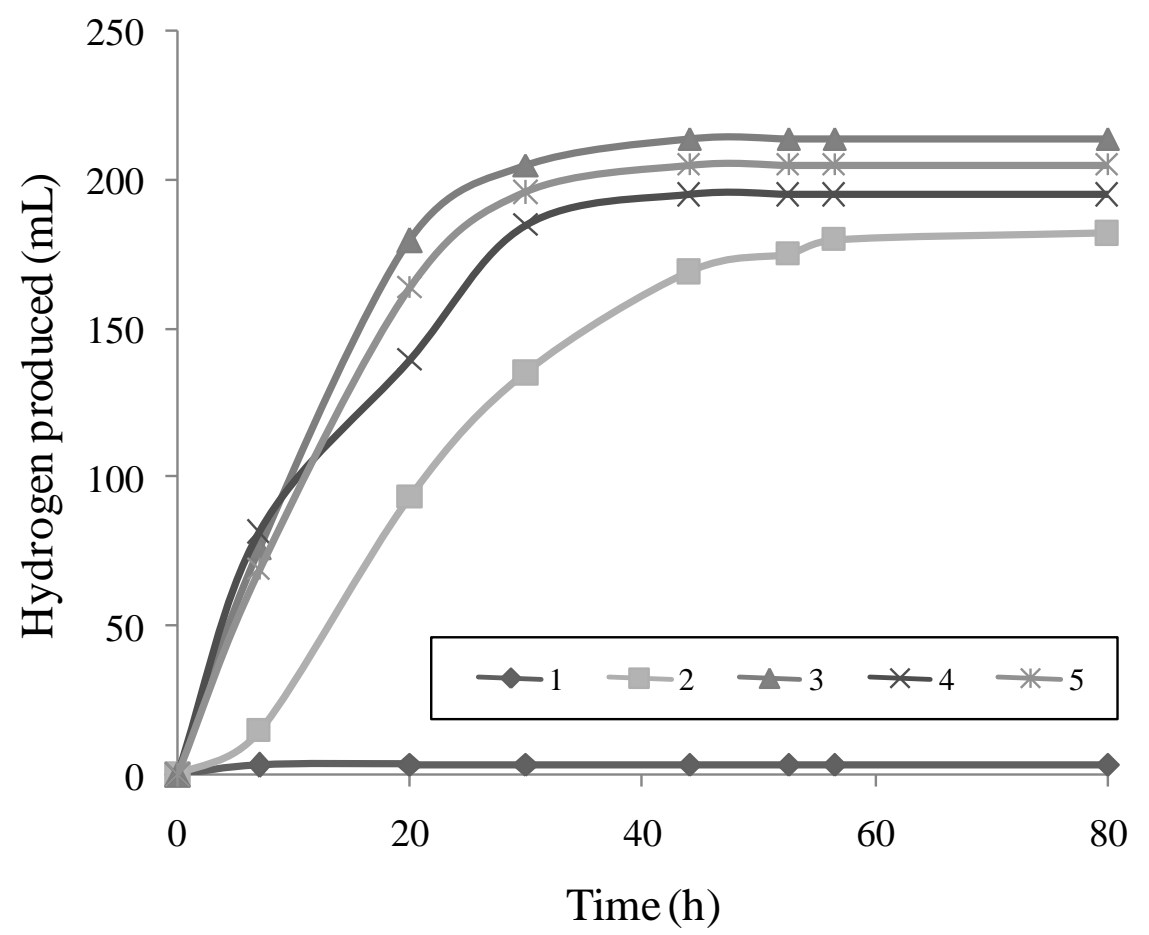

Fig. 1 


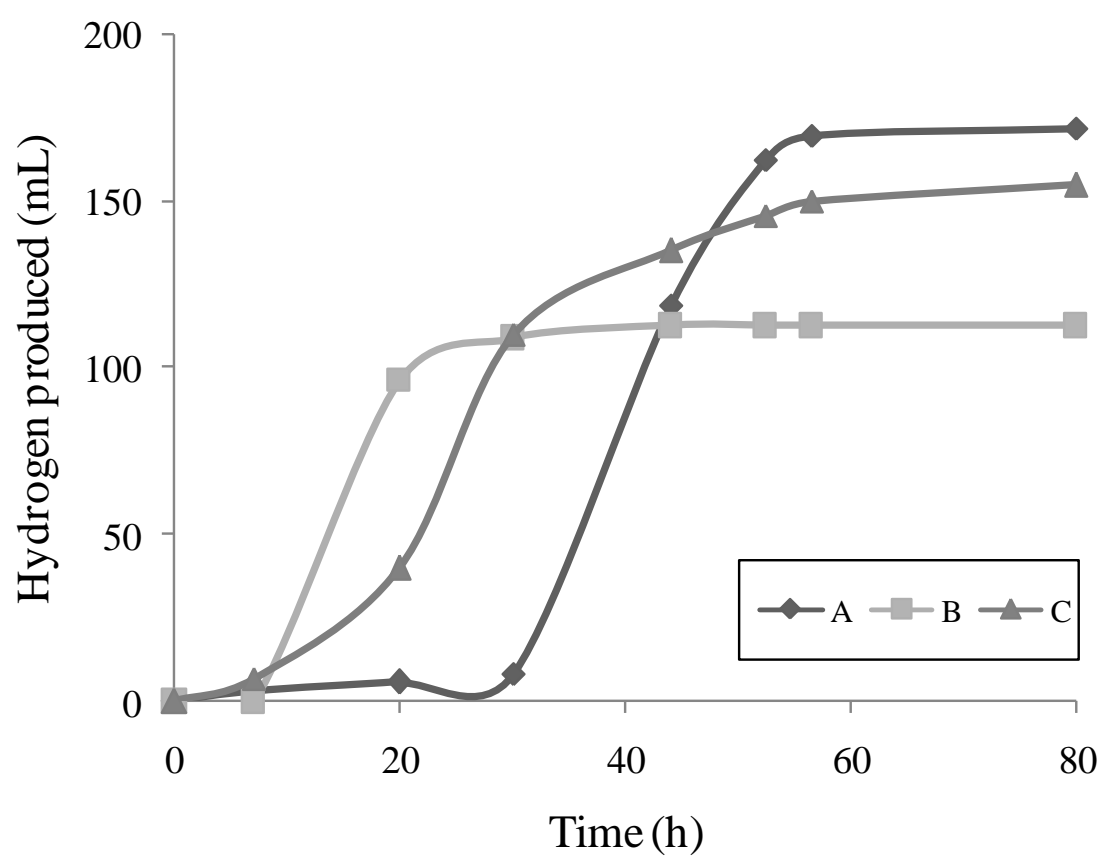

Fig. 2 


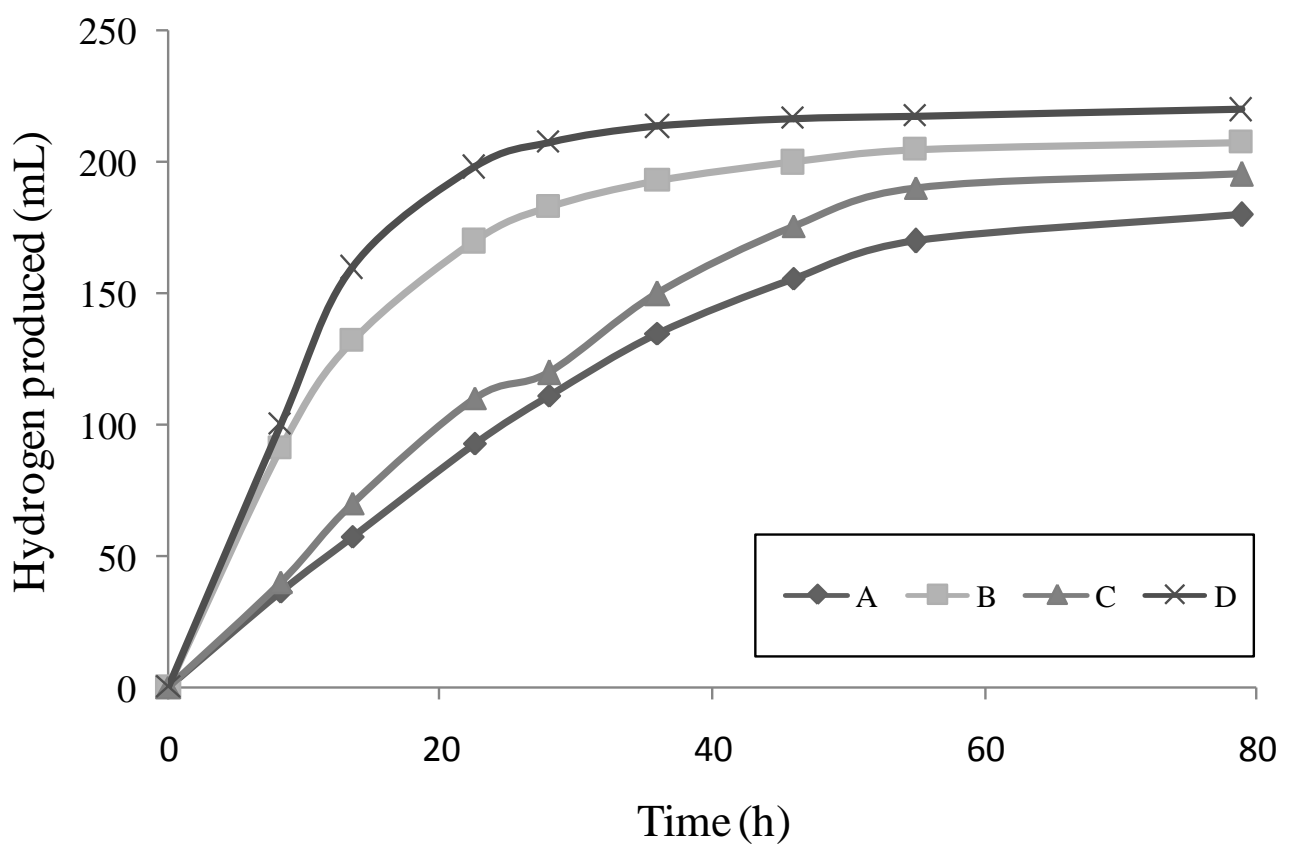

Fig. 3 


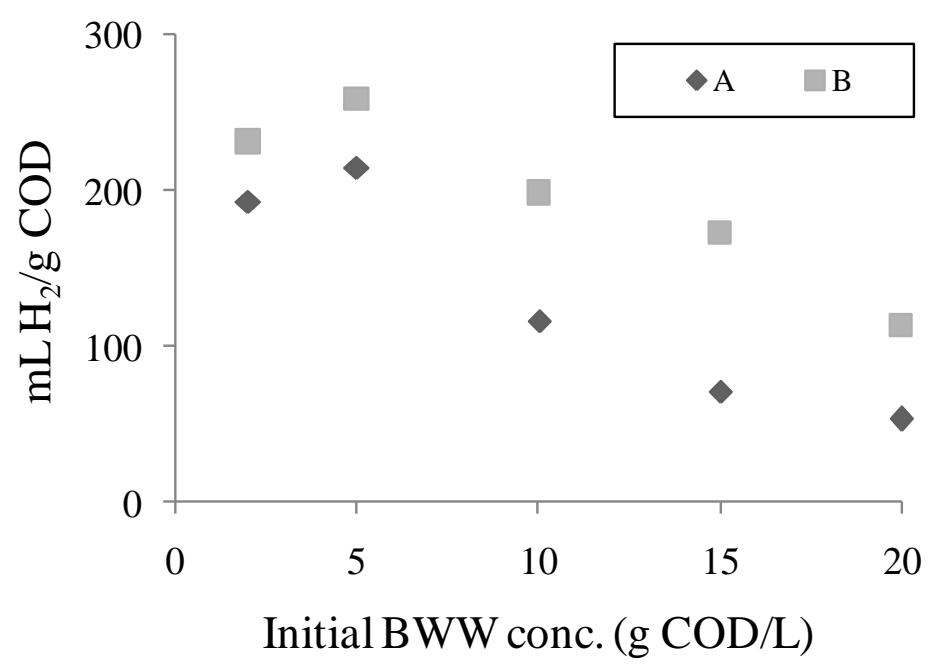

Fig. 4 


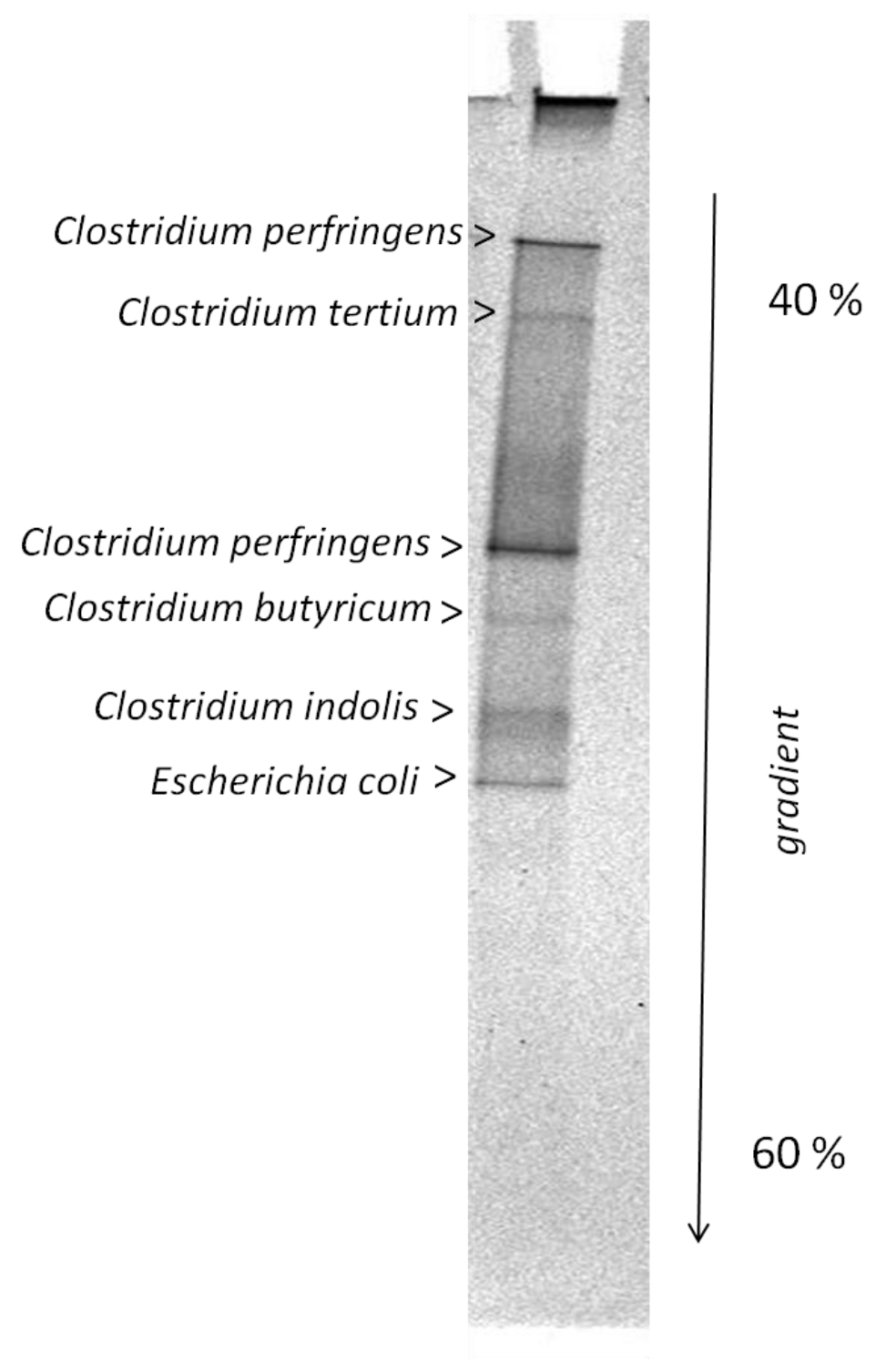

Fig.5 
Table 1 - The composition of experimental trials for Fig. 1

\begin{tabular}{llllll}
\hline & 1 & 2 & 3 & 4 & 5 \\
\hline PTS $(\mathrm{mL})$ & 20 & 20 & 20 & 20 & 20 \\
BWW (mL) & - & 20 & 20 & 20 & 20 \\
E.coli in LB (mL) & - & - & 40 & - & 20 \\
E.cloacae in LB (mL) & - & - & - & 40 & 20 \\
NS $(\mathrm{mL})$ & 5 & 5 & 5 & 5 & 5 \\
LB $(\mathrm{mL})$ & - & - & - & - & - \\
DI Water $(\mathrm{mL})$ & 135 & 115 & 75 & 75 & 75 \\
\hline Total Volume (mL) & 160 & 160 & 160 & 160 & 160 \\
\end{tabular}

PTS: Pretreated Sludge; BWW: Beverage Wastewater; NS: Nutrient Solution; LB: LuriaBertani media. 
Table 2 - The composition of experimental trials for Fig. 2

\begin{tabular}{llll}
\hline & A & B & C \\
\hline PTS (mL) & - & - & - \\
BWW (mL) & 20 & 20 & 20 \\
E.coli in LB (mL) & 40 & - & 20 \\
E.cloacae in LB (mL) & - & 40 & 20 \\
NS (mL) & 5 & 5 & 5 \\
LB (mL) & - & - & - \\
DI Water (mL) & 95 & 95 & 95 \\
\hline Total Volume (mL) & 160 & 160 & 160 \\
\hline
\end{tabular}


Table 3 - Results of the Gompertz analysis

\begin{tabular}{|c|c|c|c|c|c|c|c|c|}
\hline & \multirow[b]{2}{*}{ Conditions } & \multirow[t]{2}{*}{$\begin{array}{l}\text { Cumulative } \\
\text { hydrogen } \\
(\mathrm{mL})\end{array}$} & Modif & d Gompe & equat & ion & \multirow[t]{2}{*}{$\begin{array}{l}\mathrm{HPR} \\
\left(\mathrm{L} \mathrm{H}_{2} / \mathrm{L}-\mathrm{d}\right)\end{array}$} & \multirow[t]{2}{*}{$\begin{array}{l}\mathrm{HY} \\
\text { (mL } \mathrm{H}_{2} / \mathrm{g} \mathrm{COD} \\
\text { added) }\end{array}$} \\
\hline & & & $\begin{array}{l}\mathrm{P} \\
(\mathrm{mL}) \\
\end{array}$ & $\begin{array}{l}\mathrm{Rm} \\
(\mathrm{mL} / \mathrm{h})\end{array}$ & $\begin{array}{l}\lambda \\
(\mathrm{h}) \\
\end{array}$ & $\mathrm{R}^{2}$ & & \\
\hline \multirow{5}{*}{ Table 1} & 1 & 4 & ND & ND & ND & ND & ND & ND \\
\hline & 2 & 182 & 182 & 6.2 & 5.6 & 0.998 & 0.92 & 220.6 \\
\hline & 3 & 214 & 213.6 & 12.01 & 1 & 0.996 & 1.75 & 259.6 \\
\hline & 4 & 195 & 195.5 & 8.28 & 0.9 & 0.974 & 1.2 & 236.5 \\
\hline & 5 & 205 & 205 & 10.43 & 0.9 & 0.995 & 1.52 & 248.5 \\
\hline \multirow{3}{*}{ Table 2} & A & 172 & 176 & 10.17 & 31.4 & 0.997 & 1.48 & 208.5 \\
\hline & $\mathrm{B}$ & 113 & 112.4 & 11.18 & 9.4 & 0.999 & 1.63 & 137 \\
\hline & $\mathrm{C}$ & 155 & 150.4 & 7.15 & 14.2 & 0.993 & 1.04 & 187.8 \\
\hline
\end{tabular}

ND: Not Determined 
Table 4 - The composition of experimental trials for Fig. 3

\begin{tabular}{lllll}
\hline & A & B & C & D \\
\hline PTS (mL) & 20 & 20 & 20 & 20 \\
BWW (mL) & 20 & 20 & 20 & 20 \\
E.coli in LB (mL) & - & - & $40^{*}$ & 40 \\
NS (mL) & 5 & 5 & 5 & 5 \\
LB (mL) & - & 40 & - & - \\
DI Water (mL) & 115 & 75 & 75 & 75 \\
\hline Total Volume (mL) & 160 & 160 & 160 & 160 \\
\hline
\end{tabular}

*: $40 \mathrm{~mL}$ of LB grown overnight culture was centrifuged (12000 rpm, $5 \mathrm{~min}$ ),

3 times washed and only the obtained cell mass was added. 
Table 5 - Experimental trials for optimizing COD concentration

\begin{tabular}{|c|c|c|c|c|c|c|c|c|c|c|}
\hline & \multicolumn{3}{|c|}{ A } & & & \multicolumn{5}{|c|}{$\mathrm{B}$} \\
\hline & \multicolumn{10}{|c|}{ COD Conc. (g/L) } \\
\hline & 2 & 5 & 10 & 15 & 20 & 2 & 5 & 10 & 15 & 20 \\
\hline PTS (mL) & 20 & 20 & 20 & 20 & 20 & 20 & 20 & 20 & 20 & 20 \\
\hline $\mathrm{BWW}(\mathrm{mL})$ & 8 & 20 & 40 & 50 & 80 & 8 & 20 & 40 & 50 & 80 \\
\hline E.coli in $\mathrm{LB}(\mathrm{mL})$ & - & - & - & - & - & 40 & 40 & 40 & 40 & 40 \\
\hline $\mathrm{NS}(\mathrm{mL})$ & 5 & 5 & 5 & 5 & 5 & 5 & 5 & 5 & 5 & 5 \\
\hline DI Water (mL) & 127 & 115 & 95 & 85 & 55 & 87 & 75 & 55 & 45 & 15 \\
\hline Total Volume (mL) & 160 & 160 & 160 & 160 & 160 & 160 & 160 & 160 & 160 & 160 \\
\hline
\end{tabular}

